\title{
Evaluating AE Reporting of Two Off-Patent Biologics to Inform Future Biosimilar Naming and Reporting Practices
}

\author{
Stella Stergiopoulos ${ }^{1} \cdot$ Kenneth Getz $^{1}$
}

Published online: 25 June 2015

(c) Springer International Publishing Switzerland 2015

\begin{abstract}
Historical studies of voluntary, spontaneous drug reports show poor attribution of adverse events to generic versions of commonly prescribed medications. As biosimilars enter the market place, it may be similarly difficult to accurately attribute adverse events to their respective reference products. At this time, lack of global consensus with regard to biosimilar naming conventions may result in drug reporting confusion, misattribution of adverse events and insufficient active monitoring of safety signals. Now, with the first biosimilar approval in the USA and many biosimilars expected to be launched globally in the near future, US Food and Drug Administration (FDA) guidance on biosimilar naming conventions will be essential. To inform the FDA and the global drug development community, the Tufts Center for the Study of Drug Development (Tufts CSDD) examined primary suspect reports sent to the FDA's Adverse Event Reporting System (FAERS) from US reporters for two biologics that have lost patent exclusivity-somatropin and human insulin-and extracted 4703 insulin reports and 6487 somatropin reports from FAERS. The results show that reporting practices are inconsistent between the two biologics that were evaluated and that manufacturer identifiability and traceability are lacking. Ways to improve biosimilar naming conventions and improve reporting practices are suggested.
\end{abstract}

Kenneth Getz

kenneth.getz@tufts.edu

1 Center for the Study of Drug Development, Tufts University School of Medicine, Boston, MA, USA

\section{Key Points}

Despite strong expected growth in biosimilar approvals over the next decade, there is no global harmonization on biosimilar interchangeability and nomenclature at this time.

The US Food and Drug Administration is now considering a number of naming convention options that may facilitate global harmonization.

A retrospective study of two off-patent biologics suggests that manufacturer identifiability and traceability are lacking and that better naming conventions are needed to ensure public safety.

\section{Biosimilars and Global Interchangeability}

On 6 March 2015, the US Food and Drug Administration (FDA) approved its first biosimilar drug, Zarxio (filgrastim-sndz) [1]. The pharmaceutical industry widely views this approval as the beginning of a major growth period in biosimilar approvals during the next decade.

The FDA noted that Zarxio has been approved as a biosimilar but not as an interchangeable product (i.e. the drug cannot be substituted without healthcare provider approval) [1]. The FDA considers a biosimilar to be interchangeable with the originator biologic (i.e. the reference product) if the drug is a biosimilar, the drug will produce the same clinical result in a patient, and any safety and efficacy risks (e.g. diminished efficacy) of switching to the biosimilar are equal to or less than the risks of staying on the originator product [2]. 
The European Medicines Agency (EMA) has not made recommendations on biosimilar interchangeability. Instead, it has deferred this decision to the national level [3]. Within European Union member states, France allows for substitution when certain criteria are met (e.g. pharmacists cannot switch patients who have been started on treatment with an originator biologic) [4, 5], and the Netherlands has revised its position to allow substitution provided that the patient has been informed [6].

Elsewhere in the world, Australia's Pharmaceutical Benefits Advisory Committee (PBAC) is currently debating whether biosimilars could be substituted at the pharmacy level [7]. Both the UK and South Africa prohibit automatic substitution of biosimilars for reference products $[8,9]$. Japan also does not allow automatic substitution of biosimilars for originator biologics [10].

Regulatory agencies in the USA and Europe have also noted the importance of tracing adverse events back to the original manufacturer and biologic product for drugs that are allowed to be substituted, for drugs that are not considered interchangeable and for drugs that are considered interchangeable $[6,11,12]$. At this time, policy makers are reviewing biosimilar nomenclature to ensure patient access and safety $[13,14]$.

\section{Global Biosimilar Naming Conventions}

Despite much debate and numerous policy suggestions, there is no global harmonization on biosimilar nomenclature at the present time. In 2006, the World Health Organization (WHO) had an informal consultation on the international nonproprietary name (INN) policy for biosimilars [15] and decided "that the INN policy for biosimilars should be based on scientific considerations and that the INN system should not be altered to reflect regulatory processes. The assignment of INNs should be independent of the regulatory process or of considerations of prescribing interchangeability or the use of INNs in pharmacovigilance". In 1991, the WHO also specified different naming conventions for glycosylated and non-glycosylated proteins, whereby a Greek letter is added as a second word to the INN of glycosylated proteins $[15,16]$. The WHO also noted that use of the INN system is voluntary [16].

Currently, regulatory agencies have created their own naming conventions for biosimilars. Japan's policy includes the INN of the reference product, with a biosimilar qualifier and a code for the order of approval [17]. Specifically, biosimilars have a nonproprietary name, which includes the nonproprietary name of the originator biologic, followed by "(genetic recombination)", the INN name and the biosimilar number [18]. The brand name includes the INN, "BS" and then "Inj Content", followed by the company name [18].
The South African naming convention policy requires that the holder of the certificate of registration (HCR) "is responsible for ensuring that the product is traceable i.e. reflection of the proprietary name of the product on the adverse event reports" [8]. The UK National Institute for Health and Care Excellence (NICE) and the Medicines and Healthcare Products Regulatory Agency (MHRA) recommend "the use of brand names and lot numbers for traceability ... Any guidance on biosimilars will use brand names as substitutability and interchangeability cannot be assumed" [9, 19].

The EMA requires that each drug name (the biosimilar name and the originator biologic name) be either the trade name or the name of the active substance (i.e. the INN) together with the company name [20]. For pharmacovigilance, the EMA requires both the trade name and batch number [3, 21-23]. Additionally, the MHRA and EMA both list biosimilars and biological medicines authorized after 1 January 2011 as "medicines under additional monitoring", and they both assign a black inverted triangle to products requiring additional monitoring on the package leaflet [24, 25].

In 2014, the Expert Group of the Programme on International Nonproprietary Names at the WHO proposed a new policy on biosimilar nomenclature [16]. This new naming convention includes the INN and a voluntary fourletter random biological qualifier (BQ), which will be "assigned at random to a biological active substance manufactured at a specific site" [16]. Although this new policy was created to harmonize biosimilar nomenclature, it is not clear if other regulatory agencies (with the exception of Australia) will adopt this proposal [26]. In 2013, prior to the WHO's 2014 proposal, the Australian Therapeutic Goods Administration (TGA) required that all drugs use the Australian Approved Name (AAN) [27], i.e. it planned to combine the INN with a biosimilar qualifier containing the prefix " $\operatorname{sim}(a)-"$ and a unique three-letter identifier code as indicated by the WHO [17, 27]. As of 21 January 2015, biosimilars use "the Australian biological name without a specific biosimilar identifier suffix, for example a biosimilar to the reference product Neupogen filgrastim would be named 'TRADENAME' filgrastim" [27].

Although the FDA has approved its first biosimilar drug, the agency has noted that the name given to the biosimilar is a placeholder that should "not be reviewed as reflective of the agency's decision on a comprehensive naming policy for biosimilar and other biological products" [1]. The FDA has many options to consider. The FDA will provide a draft guidance on biological nomenclature soon, although a specific date has not been announced [1]. One option, consistent with the naming of the first FDA approved biosimilar, involves a hybrid of the INN and the 
manufacturer name [1]. Another option is to adopt the WHO's new policy. A third option may involve the creation of a unique naming system, possibly similar to that endorsed by Japan's regulatory agency. A fourth option is to use the branded name of the drug. A fifth option is to use the same INN once comparability and interchangeability have been demonstrated [28].

Advocates of the fifth option, i.e. use of the same INN for biosimilars, suggest that any other naming convention may result in less automatic substitution for interchangeable biologics [28]. Owens et al. [29] demonstrated that more than $76 \%$ of prescribers assume that drugs with the same INN are structurally identical. Fernandez-Lopez et al. [28] determined that pharmacists are more confident about substituting interchangeable biologics when both the originator biologic and the biosimilar share the same INN. Advocates instead suggest relying on brand names, lot numbers and national drug codes (NDCs) to track safety, as well as enhancements in education and technology tracking safety $[28,30]$.

Advocates of a distinguishable naming convention for biosimilars, i.e. names that are not identical, suggest that the use of identical names for biosimilars may pose public health concerns and risks due to the inability to distinguish between a biosimilar and an originator biologic in adverse event reporting [31, 32]. Advocates argue that differences in the science of biologics (as compared with smallmolecule drugs) warrant distinguishable names, as the molecules are not identical [29, 31, 32].

\section{Biologic Product-Name Attribution in the FDA's Adverse Event Reporting System (FAERS; MedWatch)}

Biosimilar nomenclature is only a part of a system that ensures patient access and safety. The traceability of a drug relies not only on the name and manufacturer but also on the lot (i.e. batch) number, which indicates when the drug was manufactured. Lot numbers help determine if potential safety signals are due to manufacturing or distribution, e.g. any changes to manufacturing processes can be determined by the lot number [14]. Biologic drugs differ from small-molecule drugs in that minor changes in the manufacturing process can change the drug's safety profile and immunogenicity [14]. Additionally, each manufacturer has a unique lot number system. If a company receives a safety report for a drug, it can use the lot number to determine if the company manufactured that drug.

FAERS asks for the drug name and the manufacturer name, as well as the lot number. The reporter, however, completes these fields voluntarily, as the reporter may not have all pertinent information available during the reporting process. A study conducted by the Tufts Center for the Study of Drug Development (Tufts CSDD) in 2012 demonstrated that these key variables are not regularly reported in FAERS [33]. The study found that of the approximately 10 million reports in FAERS, only $9 \%$ contained a lot number. The study could not determine the accuracy of lot number reports, however, as a comprehensive database containing industry drug product and lot number information does not exist [33].

In 2013, Vermeer et al. [34] corroborated these findings for biologics. They noted that traceability, as defined by reporting a batch number with the drug name, is reported in $19.9 \%$ of all biopharmaceutical drug reports, and they noted that "the current system insufficiently ensures the traceability of individual batches of biopharmaceuticals". In 2015, Grampp et al. [35] corroborated these findings for enoxaparin, stating that only $15 \%$ of adverse event reports for enoxaparin contained a lot number, and they [35] and Chao et al. [36] demonstrated that the number of adverse events for originator (branded) biologic-like drugs (e.g. enoxaparin) increased after loss of exclusivity despite the fact that sales volumes for the originator biologic-like drugs had decreased. This suggests that misattribution of adverse events had likely occurred.

In 2015, Tufts CSDD conducted a study to assess product-name attribution in two classes of drugs: somatropin (i.e. human growth hormone) and human insulin [37]. These two drugs were chosen as they are both biologics that have lost patent exclusivity and therefore may serve as proxies for biosimilar competition. However, neither of these drug classes can be automatically substituted for a generic version. Instead, the prescribing physician must indicate which brand of drug the patient will receive.

In this study, Tufts CSDD examined all primary suspect reports sent to FAERS for somatropin and human insulin from US reporters between the fourth quarter of 2005 and the third quarter of 2013. Reports were stratified by whether the drug name associated with the report contained a brand name (i.e. could be found on the FDA NDC database), a name that was attributable to a brand (i.e. could be linked to a manufacturer) or an ambiguous name (i.e. could not be linked to a manufacturer). These reports were further divided by whether or not a lot number was included in the report. The Tufts CSDD 2015 report also stratified the reports by reporter type and reporting group (e.g. direct from consumer or from the manufacturer).

The reports extracted from FAERS comprised 4703 insulin reports and 6487 somatropin reports. Of the insulin reports, $16 \%$ contained an ambiguous name, $87 \%$ of which did not report a lot number. Of all insulin reports (i.e. those not stratified by name), only $37 \%$ contained a lot number. In sum, the Tufts CSDD 2015 study found that 
$13.5 \%$ of the 4703 insulin primary suspect reports were not traceable to a manufacturer or lot number [37].

Of the somatropin reports, $8 \%$ contained an ambiguous name, $96 \%$ of which did not have an associated lot number, i.e. $7.5 \%$ of all somatropin primary reports were not traceable to a manufacturer or lot number [37]. Of all somatropin reports, only $13 \%$ contained a lot number [37].

The Tufts CSDD 2015 study demonstrated that reporting practices are not consistent across different drug types. Manufacturer identifiability was greater for somatropin reports than for insulin reports $(92 \%$ compared with $84 \%$ ), yet traceability was lower for somatropin than for insulin reports (13\% of somatropin reports had a completed lot number, compared with $37 \%$ for insulin). Vermeer et al. [34] reported similar findings for these two drug classes, with differences being explained by differences in study methodology. Both studies recognized that although insulin is not interchangeable, many reports are not attributable to a manufacturer.

Both studies also recognized the potential errors that may arise from originator drugs that are misidentified as ambiguous, and named drugs associated with a manufacturer that had been misattributed to a branded drug [14, 36-38].

\section{Conclusions and Reflections}

As the number of biosimilar applications and approvals continue to increase, the importance of collecting accurate and traceable pharmacovigilance data will continue to grow. The findings from these studies suggest that current reporting practices can and must be improved, as even drugs that are not considered bioequivalent (i.e. are prescribed by brand name, such as insulin) are not always attributed to a manufacturer correctly. A recent survey conducted by Xcenda indicated that in the USA, pharmacists currently identify biologics by NDC number [28]. This option could be viable; however, the FDA does not require that the NDC number appear on all drug labels [39]. Moreover, while the NDC number is collected on MedWatch Form 3500A [40], there is currently no variable in FAERS that contains the NDC number [38]. Thus, in its draft guidance, the FDA should consider an option that contains a company identifier, e.g. an INN with a company identifier, an INN with a BQ, a brand name or a naming system unique to the USA.

Additionally, these studies suggest that the FDA should not only consider biosimilar nomenclature but also should consider improving the reporting of lot numbers in order to ensure traceability to a company manufacturing process. One suggestion is for the agency to require manufacturing companies to provide a list of lot numbers for biologic drugs and to educate reporters on the importance of reporting an attributable (or branded) drug name associated with a manufacturer, along with the lot number [34]. Other suggestions discussed by Vermeer et al. [14] and Grampp et al. [35] include improvements in integrating databases containing product-specific medical records, electronic health records, and spontaneous adverse event reports.

Acknowledgments The authors would like to acknowledge Gustavo Grampp (Amgen Inc.), Thomas Felix (Amgen, Inc.) and Carrie A. Brown (Tufts University) for their contributions to the studies cited in the opinion piece, as well as their contributions to this opinion piece.

\section{Compliance with Ethical Standards}

Funding Tufts CSDD did not receive funding for the creation of this opinion piece but did receive two unrestricted grants for the creation of the following two publications: Getz KA, Stergiopoulos S, Kaitin KI. Evaluating the completeness and accuracy of MedWatch data. American Journal of Therapeutics. 2014 Nov-Dec;21(6):442-6. doi:10.1097/MJT.0b013e318262316f. Stergiopoulos S, Brown CA, Grampp G, Felix T, Getz KA. Identifying and quantifying the accuracy of product name attribution of US-sourced adverse event reports in MedWatch of somatropins and insulins. Therapeutic Innovation \& Regulatory Science. Epub 2015 Apr 15. http://dij.sagepub.com/ content/early/2015/04/15/2168479015578156.abstract.

Conflict of interest Stella Stergiopoulos and Kenneth A. Getz have no conflicts of interest that are directly relevant to the content of this opinion piece.

\section{References}

1. US Food and Drug Administration. FDA approves first biosimilar product Zarxio. US Food and Drug Administration. 2015 Mar 6 [cited 2015 Mar 17]. http://www.fda.gov/NewsEvents/Newsroom/ PressAnnouncements/ucm436648.htm.

2. Biologics Price Competition and Innovation Act of 2009. In: Administration FD, editor: Food Drug Administration; 2009. http://www.fda.gov/downloads/Drugs/GuidanceCompliance RegulatoryInformation/UCM216146.pdf.

3. Committee for Medicinal Products for Human Use (CHMP). Guideline on similar biological medicinal products. European Medicines Agency. 2014 Oct 23 [cited 2015 Jun 11]. http://www. ema.europa.eu/docs/en_GB/document_library/Scientific_guideline/ 2014/10/WC500176768.pdf.

4. Allin P. French biosimilar law-no generics-style substitution policy. European Biopharmaceutical Enterprises. 2014 Jan 24 [cited 2015 May 13]. http://www.ebe-biopharma.eu/newsroom/download/54/ document/ebe-bs-statement-final_24.01.2014.pdf.

5. Fox JL. Indiana jumps the biosimilars gun. Nat Biotech. 2014;32(5):406. doi:10.1038/nbt0514-406c.

6. Van den Bos H, Franken R. Netherlands MEB revises position on biosimilars and interchangeability. Biosimilars Law Blog. 2015 Apr 13 [cited 2015 May 13]. http://www.biosimilarslawblog.com/2015/ 04/13/netherlands-meb-revises-position-on-biosimilars-and-intercha ngeability-2/.

7. Schofield I. Biosimilar substitution on the table in Australia. Scrip World Pharmaceutical News. 2015 May 1 [cited 2015 May 14]. http://www.scripintelligence.com/home/Biosimilar-substitution-onthe-table-in-Australia-358168.

8. Medicines Control Council. Biosimilar medicines: quality, nonclinical and clinical requirements. Department of Health, Republic 
of South Africa. 2012 May [cited 2015 Jun 11]. http://www.mccza. com/genericDocuments/2.30_Biosimilars_Mar2012_v2.pdf.

9. Medicines and Healthcare Products Regulatory Agency. Drug safety update: biosimilar products. Drug Safety Update Feb 2008; Vol 1, Issue 7: 8 [cited 2014 Oct 9]. http://www.mhra.gov.uk/ Safetyinformation/DrugSafetyUpdate/CON084739.

10. Nagai S, Yanagihara R, Kishioka Y. Japanese regulatory authority's perspective on biosimilars. Lancet Oncol. 2015;16(3):e101.

11. Kozlowski S, Woodcock J, Midthun K. Behrman Sherman R. Developing the nation's biosimilars program. New Engl J Med. 2011;365(5):385-8.

12. Committee for Medicinal Products for Human Use. Guideline on similar biological medicinal products. European Medicines Agency. 2005 Oct 30 [cited 2015 Jun 11]. http://www.ema.europa.eu/docs/ en_GB/document_library/Scientific_guideline/2009/09/WC500003517. pdf.

13. Gaffney A. FDA stance on naming biosimilars reportedly finished, awaiting government approval. Regulatory Affairs Professionals Society. 2014 Aug 4 [cited 2015 Mar 17]. http://www.raps.org/ Regulatory-Focus/News/2014/08/04/19939/FDA-Stance-on-Nam ing-Biosimilars-Reportedly-Finished-Awaiting-GovernmentApproval/.

14. Vermeer NS, Spierings I, Mantel-Teeuwisse AK, et al. Traceability of biologicals: present challenges in pharmacovigilance. Expert Opinion Drug Saf. 2015;14(1):63-72.

15. World Health Organization. WHO informal consultation on international nonproprietary names (INN) policy for biosimilar products. World Health Organization. 2006 [cited 2015 Jun 11]. http://www. who.int/medicines/services/inn/BiosimilarsINN_Report.pdf.

16. World Health Organization. Biological qualifier: an INN proposal. Programme on International Nonproprietary Names (INN). World Health Organization. 2014 Jul [cited 2015 Jun 11]. http:// www.who.int/medicines/services/inn/bq_innproposal201407.pdf.

17. Alexander EA. The biosimilar name debate: what's at stake for public health. Generics Biosimilars Initiat J. 2014;3(1):10-2. doi:10.5639/gabij.2014.0301.005.

18. Arato T. Recent regulations of biosimilars in Japan. 47th Annual Meeting, Drug Information Association; Chicago. Pharmaceuticals and Medical Devices Agency. 2011 Jun 19-23 [cited 2015 Jun 11]. https://www.pmda.go.jp/files/000163979.pdf.

19. National Institute for Health and Care Excellence. Biosimilar technologies: NICE position statement and process to develop guidance or advice. London: National Institute for Health and Care Excellence; 2014. p. 7.

20. European Commission. What you need to know about biosimilar medicinal products: process on corporate responsibility in the field of pharmaceuticals access to medicines in Europe. European Commission. 2013 [cited 2015 Jun 11]. http://ec.europa.eu/enterprise/ sectors/healthcare/files/docs/biosimilars_report_en.pdf.

21. Commission European. Commission implementing regulation (EU) no 520/2012 of 19 June 2012 on the performance of pharmacovigilance activities provided for in regulation (EC) no 726/2004 of the European Parliament and of the Council and Directive 2001/83/EC of the European Parliament and of the Council. Official Journal of the European Union. 2012;L159:21.

22. Commission European. Directive 2001/83/EC of the European Parliament and of the Council of 6 November 2001 on the community code relating to medicinal products for human use. Official J Eur Union. 2001;L311:62.

23. European Medicines Agency. EU individual case safety report (ICSR) implementation guide. European Medicines Agency. 2014 Dec 4 [cited 2015 Jun 11]. http://www.ema.europa.eu/docs/ en_GB/document_library/Regulatory_and_procedural_guideline/ 2014/04/WC500165979.pdf.

24. European Medicines Agency. List of medicines under additional monitoring. European Medicines Agency. 2015 [cited 2015 May 14]. http://www.ema.europa.eu/ema/index.jsp?curl=pages/regulation/doc ument_listing/document_listing_000366.jsp\&mid=WC0b01ac0580 $67 \mathrm{c} 852$.

25. Medicines and Healthcare Products Regulatory Agency. The Yellow Card Scheme: guidance for healthcare professionals. Medicines and Healthcare Products Regulatory Agency. 2015 Jan 23 [cited 2015 May 14]. Available from: http://www.gov.uk/theyellow-card-scheme-guidance-for-healthcare-professionals.

26. Koenig B. Following WHO proposal, Australia suspends biosimilar naming plan. FDANews Drug Daily Bulletin. 2015 Jan 30 [cited 2015 Jun 11]. http://www.fdanews.com/articles/169741-followingwho-proposal-australia-suspends-biosimilar-naming-plan.

27. Therapeutic Goods Administration. Evaluation of biosimilars. Therapeutic Goods Administration. 2015 Apr 20 [cited 2015 May 14]. http://www.tga.gov.au/evaluation-biosimilars.

28. Fernandez-Lopez S, Kazzaz D, Bashir M, McLaughlin T. Assessment of pharmacists' views on biosimilar naming conventions. J Manag Care Spec Pharm. 2015;21(3):188-95.

29. Owens DR, Landgraf W, Schmidt A, Bretzel RG, Kuhlmann MK. The emergence of biosimilar insulin preparations - a cause for concern? Diabetes Technol Therap. 2012;14(11):989-96.

30. Generic Pharmaceutical Association. Citizen petition. Regulations.gov. 2013 Sep 17 [cited 2015 May 13]. http://www. regulations.gov/\#!documentDetail;D=FDA-2013-P-1153-0001.

31. Fitton PR. Comments of Amgen Inc. on GPhA and Novartis's citizen petitions requesting identical non-proprietary names for biological products and their respective reference products (docket nos FDA-2013-P-1153; FDA-2013-P-1398, respectively). US Food and Drug Administration. Amgen Citizen's Petition; 2013. http://www.noticeandcomment.com/FDA-2013-P-13980003-fcod-1397064.aspx.

32. DiLenge T, Radcliffe S. Re: docket no. FDA-2013-P-1153: BIO comments to Generic Pharmaceutical Association citizen petition requesting the Food and Drug Administration to implement its INN naming policy equally to all biologics. Biotechnology Industry Organization. 2014 Jan 31 [cited 2015 May 14]. http://www.bio.org/ sites/default/files/2014-01-31\%20BIO\%20Naming\%20Response\% 20GPhA\%20FINAL.pdf.

33. Getz KA, Stergiopoulos S, Kaitin KI. Evaluating the completeness and accuracy of MedWatch data. Am J Ther. 2014;21(6): 442-6. doi:10.1097/MJT.0b013e318262316f.

34. Vermeer NS, Straus SM, Mantel-Teeuwisse AK, et al. Traceability of biopharmaceuticals in spontaneous reporting systems: a cross-sectional study in the FDA Adverse Event Reporting System (FAERS) and EudraVigilance databases. Drug Saf. 2013;36(8):617-25.

35. Grampp G, Bonafede M, Felix T, Li E, Malecki M, Sprafka JM. Active and passive surveillance of enoxaparin generics: a case study relevant to biosimilars. Expert Opinion Drug Saf. 2015;14(3):349-60.

36. Chao J, Skup M, Alexander E, et al. Nomenclature and traceability debate for biosimilars: small-molecule surrogates lend support for distinguishable nonproprietary names. Adv Ther. 2015;32(3):270-83. doi:10.1007/s12325-015-0193-5.

37. Stergiopoulos S, Brown CA, Grampp G, Felix T, Getz KA. Identifying and quantifying the accuracy of product name attribution of US-sourced adverse event reports in MedWatch of somatropins and insulins. Therapeutic Innovation \& Regulatory Science. Epub 2015 Apr 15. http://dij.sagepub.com/content/early/ 2015/04/15/2168479015578156.abstract.

38. Lietzan EF, Sim LE, Alexander EA. FDLI's Food and Drug Policy Forum. Biosimilar naming: how do adverse event reporting data support the need for distinct nonproprietary names for biosimilars? Food and Drug Law Institute. 2013 Mar 27 [cited 2015 Jun 11]. http://www.fdli.org/docs/default-document-library/ lietzan-faers-bio-final-3-27-13.pdf. 
39. US Food and Drug Administration. Code of Federal Regulations title 21-food and drugs. Chapter I-Food and Drug Administration, Department of Health and Human Services. Subchapter C - drugs: general. Part 207, subpart C-procedures for domestic drug establishments. US Food and Drug Administration. 2014 Sep 1 [cited 2015 Jun 11]. http://www.accessdata.fda.gov/scripts/cdrh/cfdocs/
cfcfr/CFRSearch.cfm?CFRPart=207\&showFR=1\&subpartNode= 21:4.0.1.1.7.3.

40. US Food and Drug Administration. Form FDA 3500A. US Food and Drug Administration. 2013 Feb [cited 2015 Mar 14]. http:// www.fda.gov/downloads/AboutFDA/ReportsManualsForms/Forms/ UCM295636.pdf. 